\title{
A Prospective Comparative Study of Mobile Acoustic Uroflowmetry and Conventional Uroflowmetry
}

\author{
Dong-Gi Lee ${ }^{1,2}$, Jonathan Gerber ${ }^{1}$, Vinaya Bhatia ${ }^{1}$, Nicolette Janzen ${ }^{1}$, Paul F. Austin ${ }^{1}$, Chester J. Koh ${ }^{1}$, Sang Hoon Song ${ }^{1,3}$ \\ ${ }^{1}$ Division of Pediatric Urology, Department of Surgery, Texas Children's Hospital, and Scott Department of Urology, Baylor College of Medicine, Houston, TX, \\ USA \\ ${ }^{2}$ Department of Urology, Kyung Hee University School of Medicine, Seoul, Korea \\ ${ }^{3}$ Department of Urology, Asan Medical Center, University of Ulsan College of Medicine, Seoul, Korea
}

\begin{abstract}
Purpose: The aim of this study was to assess the performance of a mobile acoustic Uroflowmetry (UFM) application compared with standard UFM in the pediatric population.

Methods: A mobile acoustic UFM application represents a noninvasive method to estimate the urine flow rate by recording voiding sounds with a smartphone. Male pediatric patients who were undergoing UFM testing were prospectively recruited, and the voiding sounds were recorded and analyzed. The intraclass correlation coefficient (ICC) was used to compare the maximum flow rate (Qmax), average flow rate (Qavg), voiding time (VT), and voiding volume (VV) as estimated by acoustic UFM with those calculated by standard UFM. Differences in Qmax, Qavg, VT, and VV between the 2 UFM tests were determined using 95\% Bland-Altman limits of agreement.

Results: A total of 16 male patients were evaluated. Their median age was 9 years. With standard UFM, the median Qmax, Qavg, VT, and VV were $18.7 \mathrm{~mL} / \mathrm{sec}, 11.1 \mathrm{~mL} / \mathrm{sec}, 15.2$ seconds, and $157.8 \mathrm{~mL}$, respectively. Strong correlations were observed between the 2 methods for $\mathrm{Qmax}(\mathrm{ICC}=0.755, \mathrm{P}=0.005)$, VT (ICC $=0.974, \mathrm{P}<0.001)$, and VV (ICC $=0.930, \mathrm{P}<0.001)$, but not for Qavg (ICC $=0.442, \mathrm{P}=0.135$ ). The Bland-Altman plot showed good agreement between the 2 UFM tests. Flow patterns recorded by acoustic UFM and conventional UFM showed good visual correlations.

Conclusions: Acoustic UFM was comparable to standard UFM for male pediatric patients. Further validation of its performance in different toilet settings is necessary for broader use.
\end{abstract}

Keywords: Urodynamics; Mobile applications; Sound; Software

- Fund/Grant Support: This study was partially supported by a grant (2017IT0536-1) from the Asan Institute for Life Sciences, Asan Medical Center, Seoul, Korea.

- Research Ethics: This prospective comparative study was approved by the Institutional Review Board of Texas Children's Hospital (Protocol H-45455). Informed consent was obtained for all participants or parents.

- Conflict of Interest: No potential conflict of interest relevant to this article was reported.

\section{INTRODUCTION}

Lower urinary tract (LUT) symptoms have been reported to be present in as many as $20 \%$ of school-aged children in epidemiological studies [1]. Uroflowmetry (UFM) with postvoid residual
(PVR) urine measurements is an essential noninvasive diagnostic method for LUT symptoms in both adult and pediatric populations [2]. UFM is used to assess the amount of urine voided and the flow rate of urination by collecting urine voided into a funnel-shaped device or a specialized toilet in the clinic

Corresponding author: Sang Hoon Song (iD https://orcid.org/0000-0003-4888-483X Department of Urology, Asan Medical Center, University of Ulsan College of Medicine, 13 Gangdong-daero, Songpa-gu, Seoul 05535, Korea Email: mdexodus@naver.com

Submitted: April 30, 2021 / Accepted after revision: July 9, 2021 
setting.

Standard UFM is sometimes inconvenient for children because it requires patients to arrive at the clinic with a fairly full bladder. According to the International Children's Continence Society (ICCS), the voiding volume (VV) should be $\geq 50 \%$ of the age-dependent estimated bladder capacity in children to be relevant for interpretation [3]. When the bladder is not full, the patient has to remain longer in the clinic for fluid intake until the bladder volume is large enough for a reliable study. Some children are unable to avoid bladder emptying just prior to the test; thus, delaying or canceling the test is a relatively common occurrence. Because 2 or more tests are recommended for accuracy and consistency, children and their parents often must visit a clinic for repeat studies [3]. In the coronavirus disease 2019 pandemic era, in-clinic UFM could be especially challenging because this test can be time- and cost-consuming with the need for repeated in-person visits to a hospital or clinic environment [4]. Moreover, compared with their home environment, the clinic test environment may be unfamiliar or uncomfortable for children, hindering their ability to void well at the appointed time.

Sound-based UFM is a new approach that records and analyzes the sound of a urine stream hitting the surface of the toilet bowl or the water in it, which provides estimates of flow parameters such as the maximum flow rate (Qmax), voiding time (VT), and VV. In previous studies, sound-based UFM demonstrated validity in healthy men and women $[5,6]$. However, its validity and applicability have not been previously described in pediatric patients. This study aimed to assess the performance of a novel mobile acoustic UFM (mUFM) application compared with standard UFM in the pediatric population.

\section{MATERIALS AND METHODS}

\section{Mobile Acoustic UFM System}

An Institutional Review Board-approved prospective comparative study was performed using mUFM, which is a simple, noninvasive method for estimating the urinary flow by recording the sound of voiding with a smartphone. The PRIVY Urine Flow Monitor application (Soundable Health, San Francisco, CA, USA) records sound data and processes the signals to generate a flow curve using an algorithm developed by machine learning methods (Fig. 1). It includes a background noise removal algorithm based on frequency band analysis and feature extraction at specific time steps. At each time step, the flow rate is calculated based on the sound parameters, where the sound

\section{Data Acquisition}
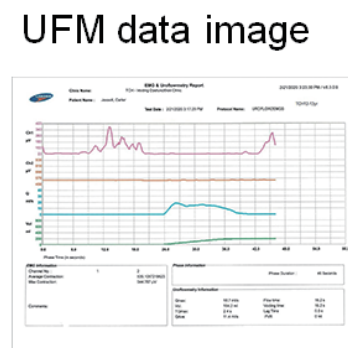

Audio data

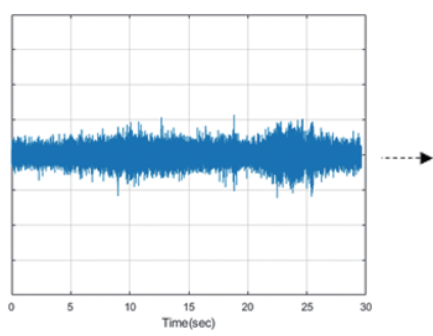

Data Pre-processing

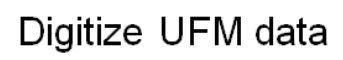

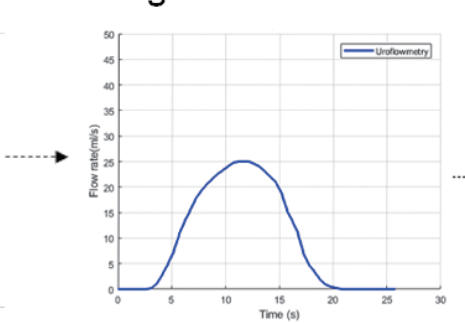

Flow prediction modeling Modeling

Application

\section{Evaluation \& validation}

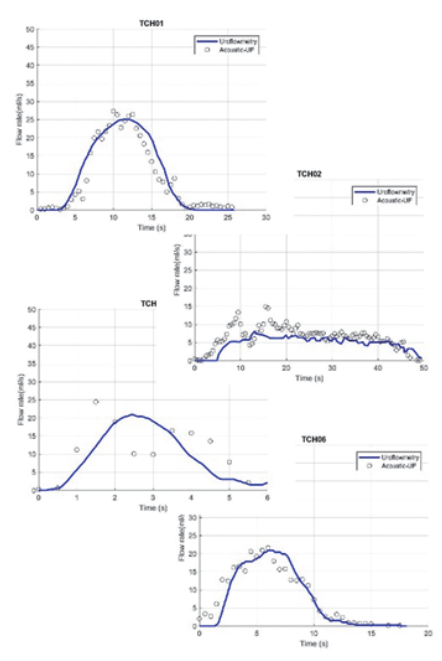

Remove noise Feature Extraction

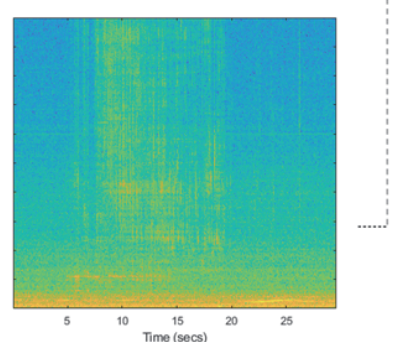

Apply to test cases
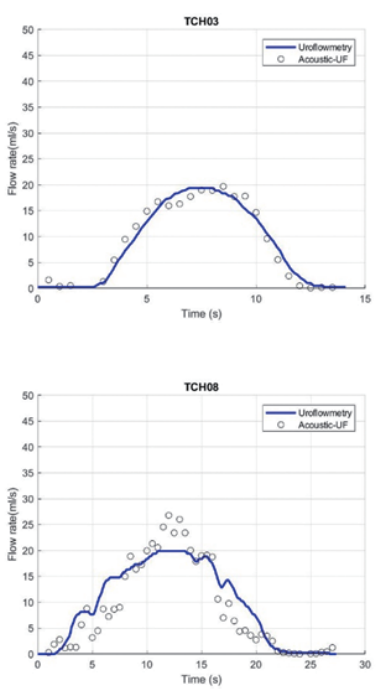

Fig. 1. Sound data acquisition and data processing. UFM, uroflowmetry. 
is classified as urination. The application reports VT based on the duration of the urine flow, VV based on the calculated area under the curve, and Qmax based on the peak flow rate of the estimated flow curve. The accuracy of this application was previously validated in an adult population consisting of 66 men and 46 women $[7,8]$. In this pediatric study, we applied the flow prediction model using sound data from pediatric patients and used it to generate a predicted flow curve.

\section{Study Population}

This prospective comparative study was approved by the Institutional Review Board of Texas Children's Hospital (Protocol $\mathrm{H}$-45455). Informed consent was obtained for all participants or parents before the UFM test. We included male children up to 18 years in age who underwent UFM with electromyography (EMG) and PVR measurements as part of their pediatric urology evaluation. We included only male children and had them urinate only in standing position to standardize the study protocol as much as possible. We excluded patients with neurogenic bladder dysfunction from this preliminary study.

\section{Test Environment Setup}

After providing informed consent, all subjects underwent UFM with EMG in a urodynamic study room. Experienced nurses performed UFM with an EMG evaluation using the Urostym or Triton system (Laborie Medical Technologies, Toronto, ON, Canada). The patients changed into a gown before evaluation. Real-time bladder ultrasonography was performed to measure the bladder volume before the UFM test. When the bladder volume was over $100 \mathrm{~mL}$, the patients were encouraged to start voiding into the funnel receptacle behind a curtain in the UFM test room. EMG patches were attached to their perineum and lower abdominal area. Before the test, we placed a smartphone (iPhone; Apple Inc., Cupertino, CA, USA), which was held by a clamp attached to an upright rod that was at a consistent location $30 \mathrm{~cm}$ away from the funnel for all patients. The application recorded sounds during urination (Fig. 2).

\section{Data Acquisition and Analysis}

The application on the smartphone was started by the study personnel a few seconds before the patients began to stand in front of the funnel. The patients were asked to urinate into a funnel connected to the uroflowmeter. The application synchronously recorded the sound of voiding and automatically saved the data. mUFM results such as the Qmax, average flow
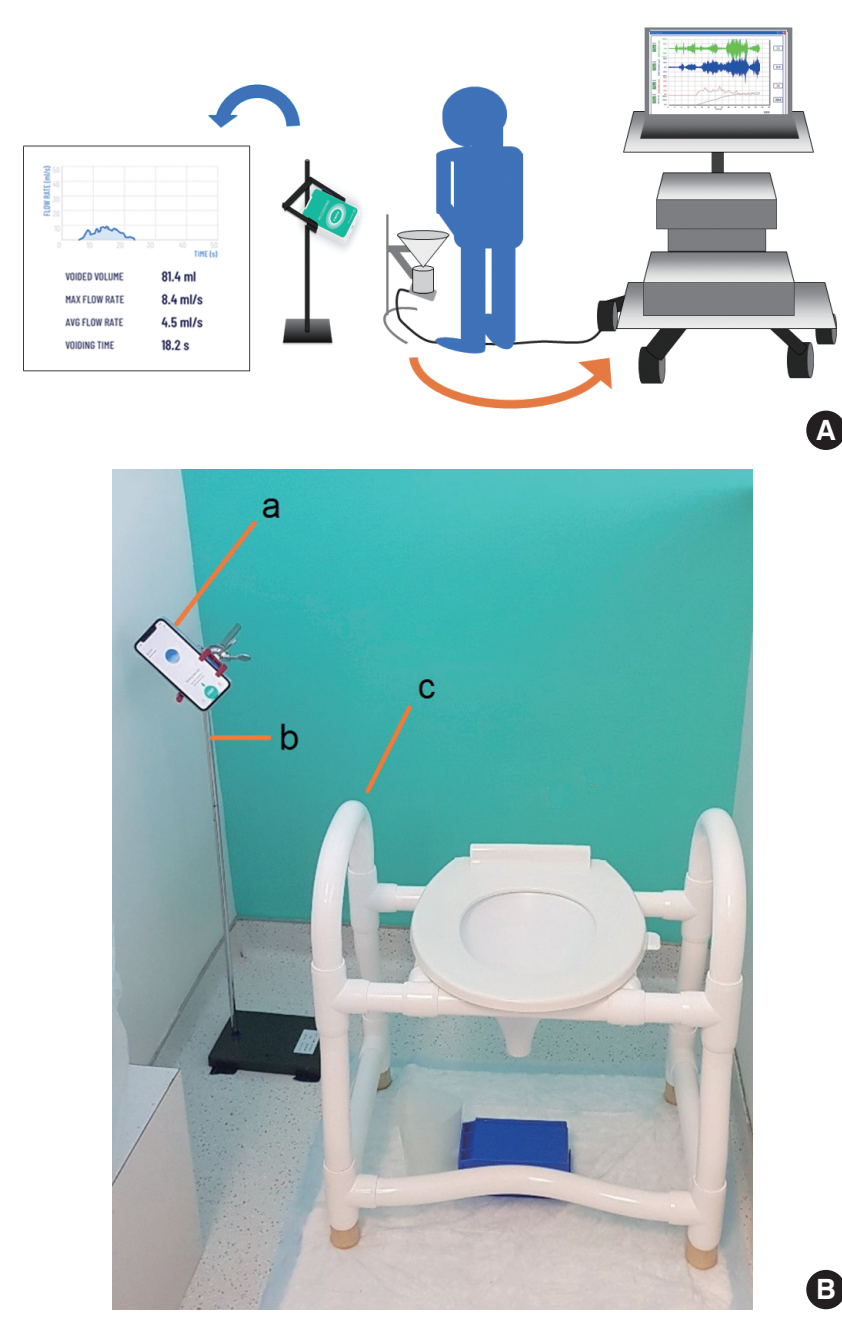

B

Fig. 2. Mimetic diagram (A) and picture of the smartphone (B) attached to an upright rod (a) and clamp (b) showing the uroflowmetry test environment and the smartphone setting. The rod and clamp (a, b), as well as the urinal for uroflowmetry testing (c), were located in the same place marked on the ground in the uroflowmetry room for every subject.

rate (Qavg), VT, and VV were automatically estimated by the algorithm embedded in the mUFM application. The intraclass correlation coefficient (ICC) was used to compare Qmax, Qavg, VT, and VV estimated by standard UFM with those calculated by acoustic UFM. The agreement of Qmax, Qavg, VT, and VV between the 2 UFM tests was assessed using Bland-Altman plots, and the mean differences and the $95 \%$ limits of agreement (mean difference \pm 1.96 standard deviations) were determined. A linear regression analysis was conducted using differences in parameters between UFM and mUFM as the dependent variable, and the average parameters of the measurements as the independent variable to identify any proportional bias. 
Table 1. Primary diagnoses, clinical parameters, and uroflowmetry data

\begin{tabular}{|c|c|c|c|c|c|c|c|c|c|c|}
\hline No. & $\begin{array}{l}\text { Age } \\
(\mathrm{yr})\end{array}$ & Primary diagnosis & Past medical history & $\begin{array}{c}\text { Qmax } \\
(\mathrm{mL} / \mathrm{sec})\end{array}$ & $\begin{array}{c}\text { Qave } \\
(\mathrm{mL} / \mathrm{sec})\end{array}$ & $\begin{array}{l}\mathrm{VV} \\
(\mathrm{mL})\end{array}$ & $\begin{array}{c}\text { TQmax } \\
(\mathrm{sec})\end{array}$ & $\begin{array}{l}\text { FT } \\
(\mathrm{sec})\end{array}$ & $\begin{array}{l}\text { VT } \\
(\mathrm{sec})\end{array}$ & PVR \\
\hline 1 & 12 & Bladder bowel dysfunction & $\begin{array}{l}\text { UTI, ADHD, s/p } \\
\text { cryptorchidism }\end{array}$ & 24.9 & 14.1 & 247.1 & 56 & 17.6 & 64.5 & 0 \\
\hline 2 & 8 & $\begin{array}{l}\text { Urinary frequency, urgency, } \\
\text { urge incontinence }\end{array}$ & s/p hypospadias repair & 8.1 & 5.5 & 247 & 7.7 & 44.6 & 44.6 & 17 \\
\hline 3 & 4 & $\begin{array}{l}\text { Urinary frequency, urgency, } \\
\text { urge incontinence }\end{array}$ & None & 19.6 & 11.7 & 121.4 & 4.8 & 10.4 & 10.4 & 14 \\
\hline 4 & 7 & $\begin{array}{l}\text { Urinary frequency, urge } \\
\text { incontinence }\end{array}$ & Speech delay & 20.6 & 6.7 & 62.6 & 2 & 9.3 & 14 & 0 \\
\hline 5 & 5 & $\begin{array}{l}\text { Nocturnal enuresis, daytime } \\
\text { incontinence }\end{array}$ & None & 14.7 & 6 & 74.3 & 4.7 & 12.5 & 12.8 & 0 \\
\hline 6 & 7 & Urge incontinence, enuresis & $\mathrm{s} / \mathrm{p}$ tonsillectomy & 20.8 & 11.4 & 137.2 & 4.7 & 12 & 12 & 0 \\
\hline 7 & 10 & Urinary incontinence & Asthma, encopresis & 27.2 & 14.5 & 137 & 3.5 & 9.5 & 9.5 & 40 \\
\hline 8 & 11 & $\begin{array}{l}\text { Dysuria, urinary urgency, } \\
\text { recurrent enuresis }\end{array}$ & None & 19.8 & 12.3 & 258.8 & 10.2 & 21 & 21 & 0 \\
\hline 9 & 12 & Urinary incontinence & None & 18.4 & 12.1 & 152.9 & 5.1 & 12.6 & 12.6 & 15 \\
\hline 10 & 7 & Urinary incontinence & $\begin{array}{l}\text { Craniosynostosis, } \\
\text { prematurity }\end{array}$ & 10.7 & 5.7 & 97.4 & 14.3 & 17.1 & 17.4 & 0 \\
\hline 11 & 18 & $\begin{array}{l}\text { Urinary urgency and frequency, } \\
\text { straining to urinate }\end{array}$ & None & 21.4 & 10.9 & 180.3 & 5.9 & 16.6 & 16.6 & 110 \\
\hline 12 & 13 & Nocturnal enuresis & Autism spectrum disorder & 18.7 & 11.4 & 184.2 & 2.4 & 16.2 & 16.2 & 0 \\
\hline 13 & 7 & Nocturnal enuresis & s/p hypospadias repair & 16.8 & 7.2 & 81 & 4.9 & 11.3 & 12.4 & 0 \\
\hline 14 & 12 & Urethral stricture & s/p hypospadias repair & 15.8 & 9.1 & 274.7 & 18.4 & 30.1 & 33.2 & 0 \\
\hline 15 & 7 & $\begin{array}{l}\text { Urinary incontinence, } \\
\text { encopresis }\end{array}$ & None & 18.8 & 11.3 & 162.7 & 3.5 & 14.3 & 18.2 & 30 \\
\hline 16 & 10 & Urinary incontinence & $\begin{array}{l}\text { ADHD, s/p valve ablation } \\
\text { for PUV }\end{array}$ & 16 & 8.7 & 167.7 & 10.2 & 19.1 & 22.4 & 20 \\
\hline
\end{tabular}

Qmax, maximum flow rate; Qave, average flow rate; VV, voided volume; TQmax, time to maximal flow rate; FT, flow time; VT, voiding time; PVR, postvoid residual urine; UTI, urinary tract infection; ADHD, attention-deficit hyperactivity disorder; PUV, posterior urethral valve; s/p, status post.

We visually compared the pattern of the flow curves between UFM and mUFM. All statistical analyses were performed with IBM SPSS Statistics ver. 25.0 (IBM Co., Armonk, NY, USA) and the Bland-Altman plots were plotted using MedCalc (MedCalc Software, Ostend, Belgium).

\section{RESULTS}

A total of 16 male pediatric patients were included in this prospective study. All patients underwent UFM due to LUT symptoms. Of these patients, 8 patients (50\%) reported daytime urinary incontinence, and 4 patients (25\%) reported nocturnal enuresis as the chief complaint. In addition, 3 patients (18.7\%) had a history of hypospadias repair, and 1 patient $(6.2 \%)$ had a history of endoscopic valve ablation of posterior urethral valves (Table 1).

The patients' median age was 9 years, and they had a median Qmax of $18.7 \mathrm{~mL} / \mathrm{sec}$ (range, 8.1-27.2 mL/sec), a median Qavg of $11.1 \mathrm{~mL} / \mathrm{sec}$ (range, $5.5-14.5 \mathrm{~mL} / \mathrm{sec}$ ), a median VT of 15.2 seconds (range, 9.5-44.6 seconds), and a median VV of 157.8 $\mathrm{mL}$ (range, 62.6-274.7 mL).

Strong correlations were observed between the 2 methods for Qmax $(\mathrm{ICC}=0.755, \mathrm{P}=0.005)$, VT $(\mathrm{ICC}=0.974, \mathrm{P}<0.001)$, and VV (ICC $=0.930, P<0.001)$, but not for Qavg $(\mathrm{ICC}=0.442$, $\mathrm{P}=0.135)$. The Bland-Altman plots of measurements, which represent the relationship between the differences and mean values determined by the 2 UFM tests, are shown in Fig. 3. Regarding Qmax, the mean difference and 95\% limits of agree- 

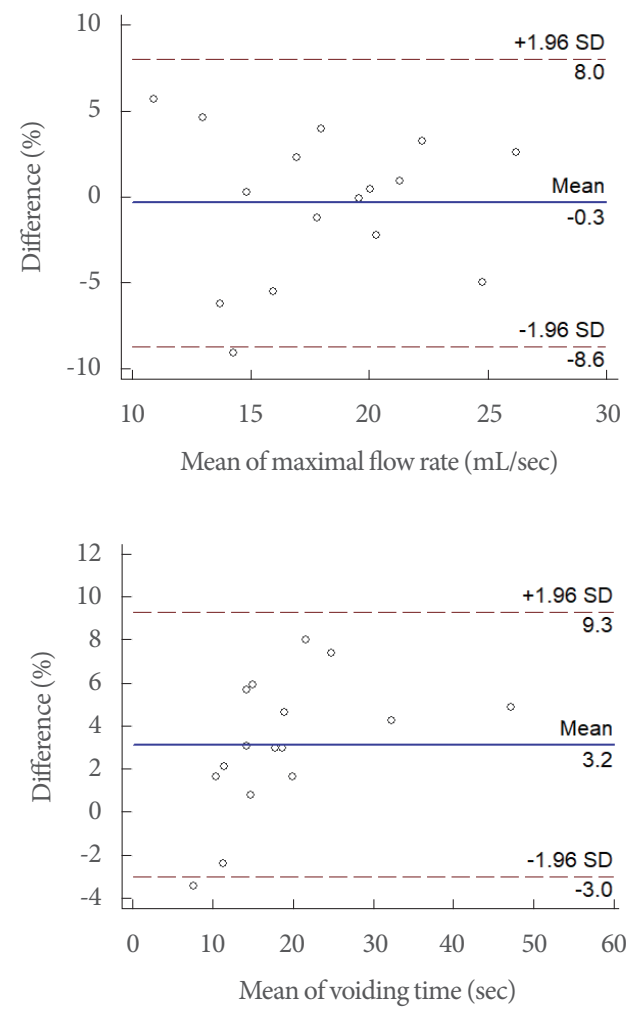

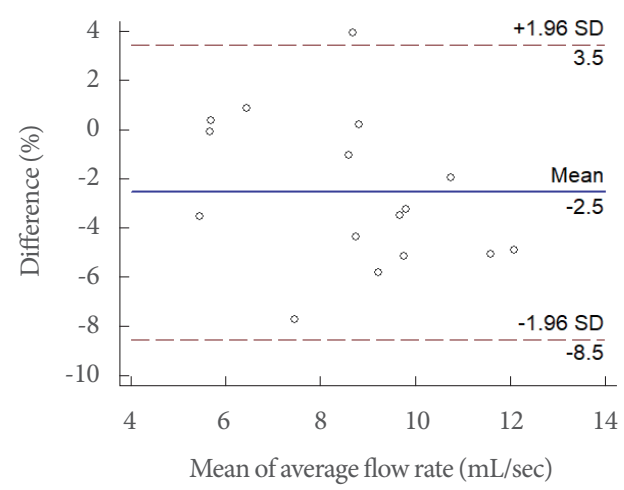

B

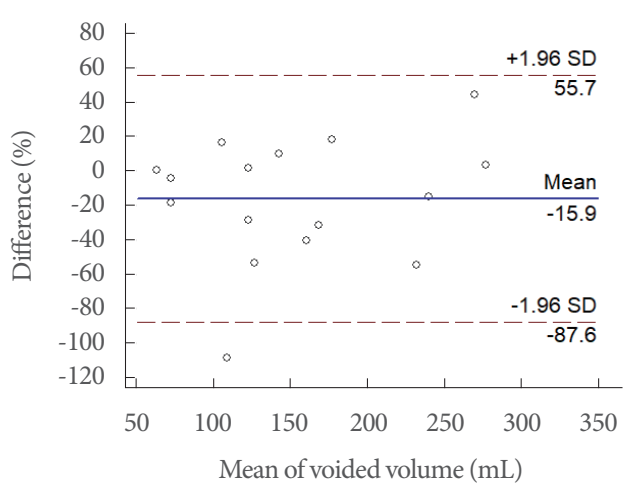

(D)

Fig. 3. Bland-Altman plots of agreement between mobile acoustic uroflowmetry and standard uroflowmetry for maximum flow rate (Qmax), average flow rate (Qavg), voiding time (VT), and voided volume (VV). Bland-Altman plots of Qmax (A), Qavg (B), VT (C), and VV (D) show the relationships between the 2 uroflowmetry tests. The difference (y-axis) between the 2 uroflowmetry tests is plotted against the mean value (x-axis) of 2 uroflowmetry parameters. The solid blue line indicates the mean difference. The top and bottom dashed lines correspond to the upper and lower margins of $95 \%$ limits of agreement. SD, standard deviation.

Table 2. Linear regression of the mean difference and the mean of Qmax, Qavg, VT, and VV

\begin{tabular}{lccccc}
\hline Variable & $\mathrm{B}$ & Standardized error & Beta & $\mathrm{t}$ & $\mathrm{P}$-value \\
\hline Qmax & 0.021 & 0.265 & 0.021 & 0.078 & 0.939 \\
Qavg & -0.549 & 0.375 & -0.365 & -1.467 & 0.165 \\
VT & 0.159 & 0.075 & 0.491 & 2.11 & 0.053 \\
VV & 0.109 & 0.139 & 0.205 & 0.785 & 0.446 \\
\hline
\end{tabular}

Qmax, maximum flow rate; Qavg, average flow rate; VT, voiding time; VV, voided volume.

ment were $-0.3 \mathrm{~mL} / \mathrm{sec}$ and $-8.6 \mathrm{~mL} / \mathrm{sec}$ to $8.0 \mathrm{~mL} / \mathrm{sec}$, respectively; for Qavg, the mean difference and $95 \%$ limits of agreement were $-2.5 \mathrm{~mL} / \mathrm{sec}$ and $-8.5 \mathrm{~mL} / \mathrm{sec}$ to $3.5 \mathrm{~mL} / \mathrm{sec}$, respectively; for VT, the mean difference and $95 \%$ limits of agreement were 3.2 seconds and -3.0 seconds to 9.3 seconds, respectively; and for $\mathrm{VV}$, the mean difference and $95 \%$ limits of agreement were $-15.9 \mathrm{~mL}$ and $-87.6 \mathrm{~mL}$ to $55.7 \mathrm{~mL}$, respectively. Linear regression of the mean difference and the mean values of parameters of UFM and mUFM showed no statistical significance, in- dicating that no proportional bias was seen (Table 2). The flow patterns recorded by UFM and mUFM showed good visual correlations (Fig. 4).

\section{DISCUSSION}

This pilot study is the first prospective study to demonstrate the feasibility and validity of mUFM in the male pediatric population. The mUFM application was easily accessible and compa- 

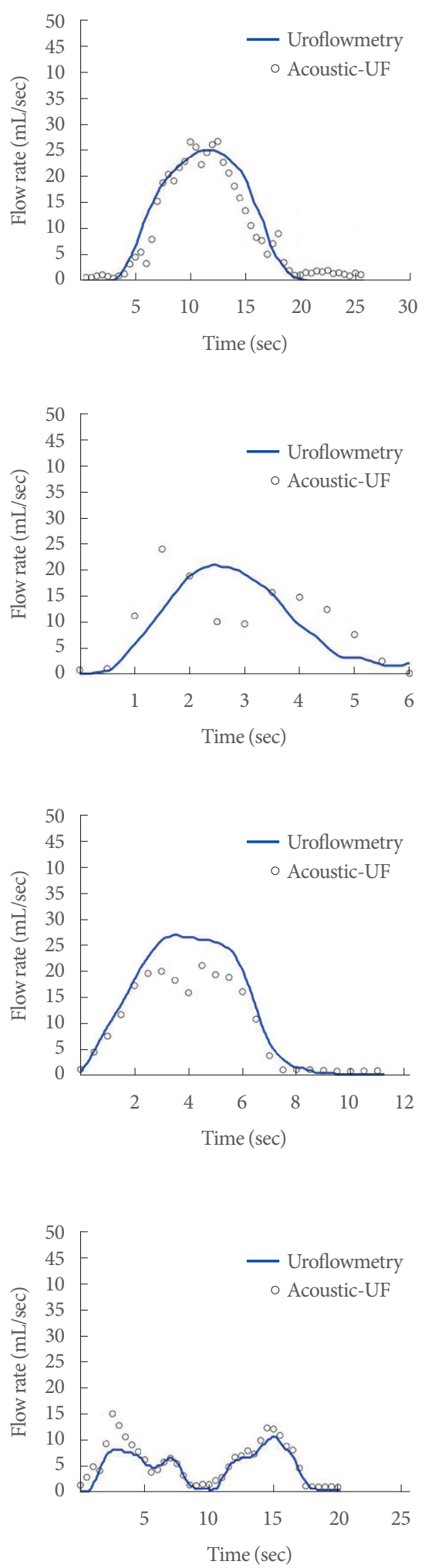

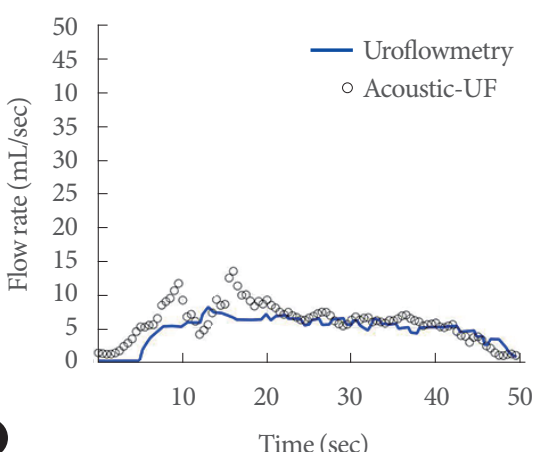

B
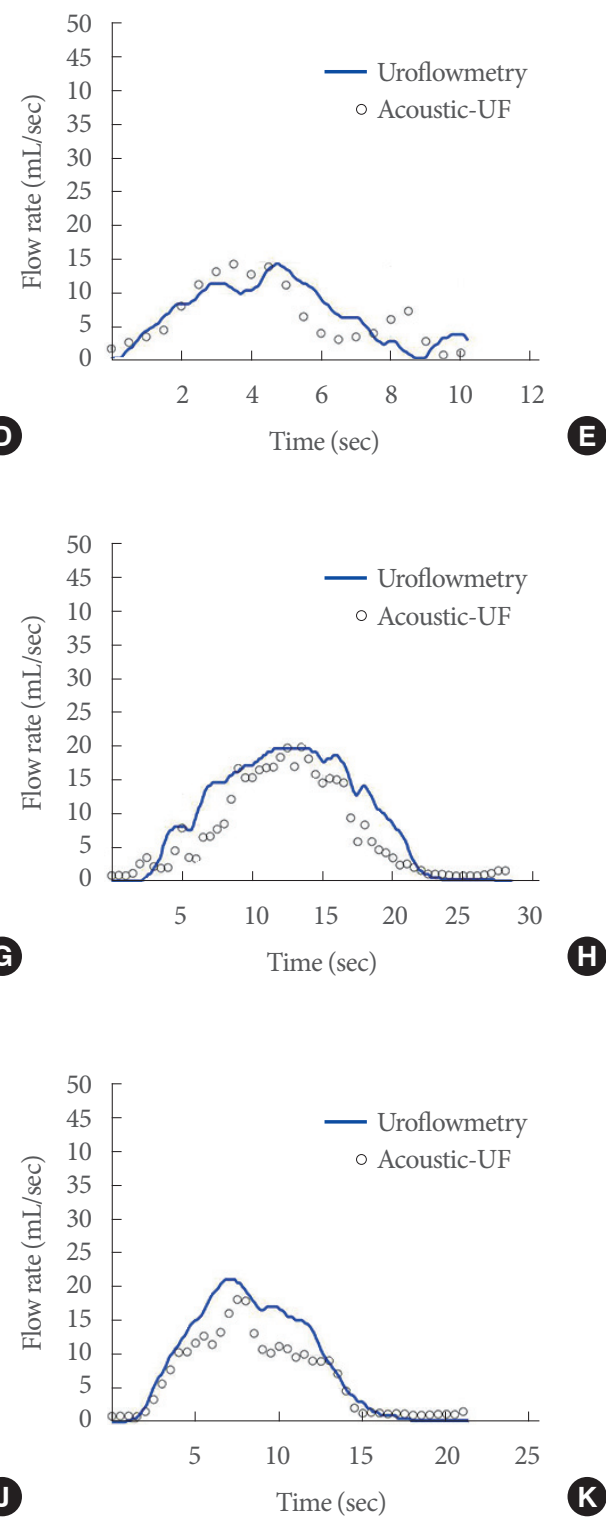

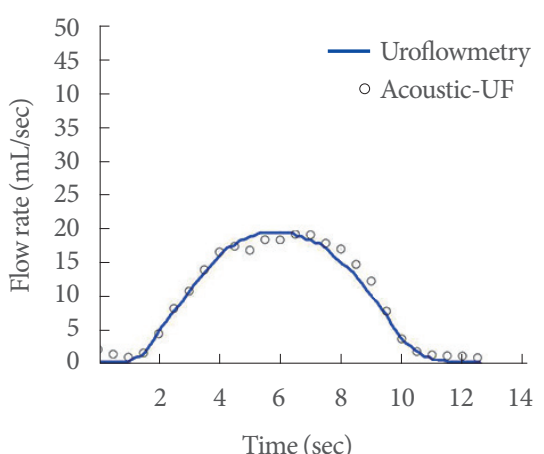

C
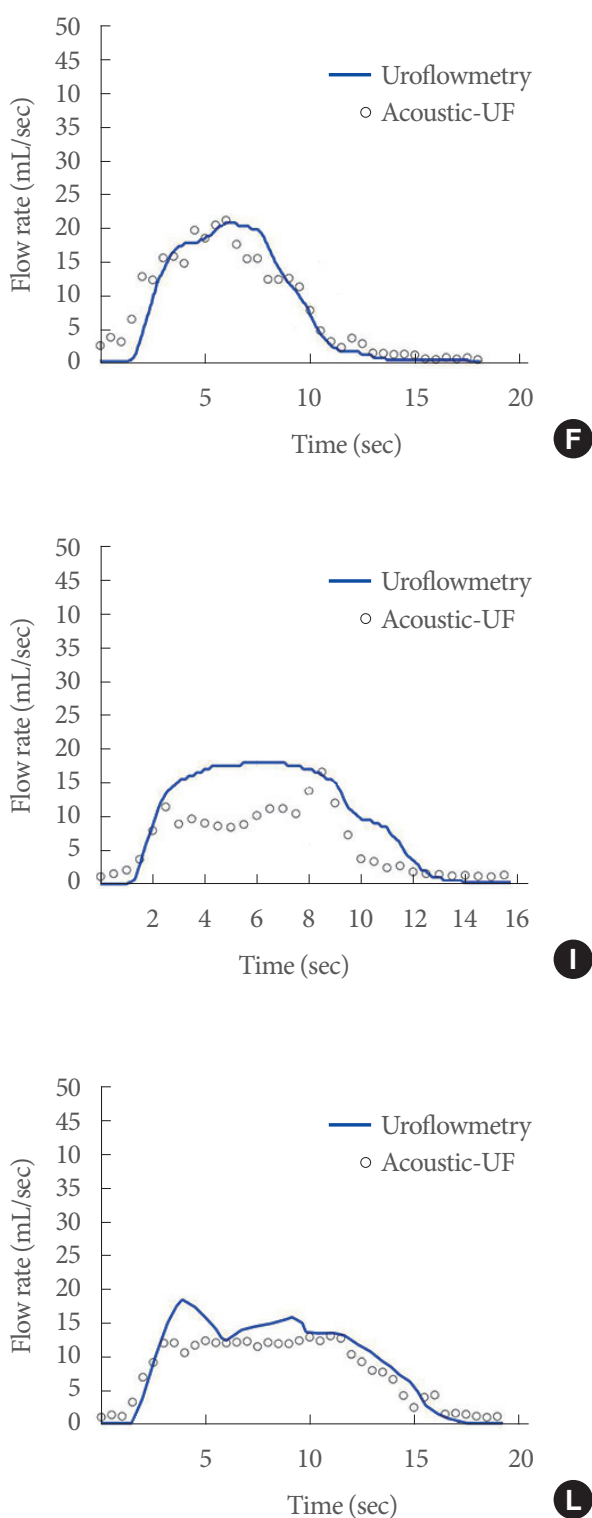

(Continued)

Fig. 4. Visual correlation of representative flow patterns recorded by uroflowmetry and mobile acoustic uroflowmetry (UF). Panels A-P are corresponding flow patterns of patient number 1 to 16. 

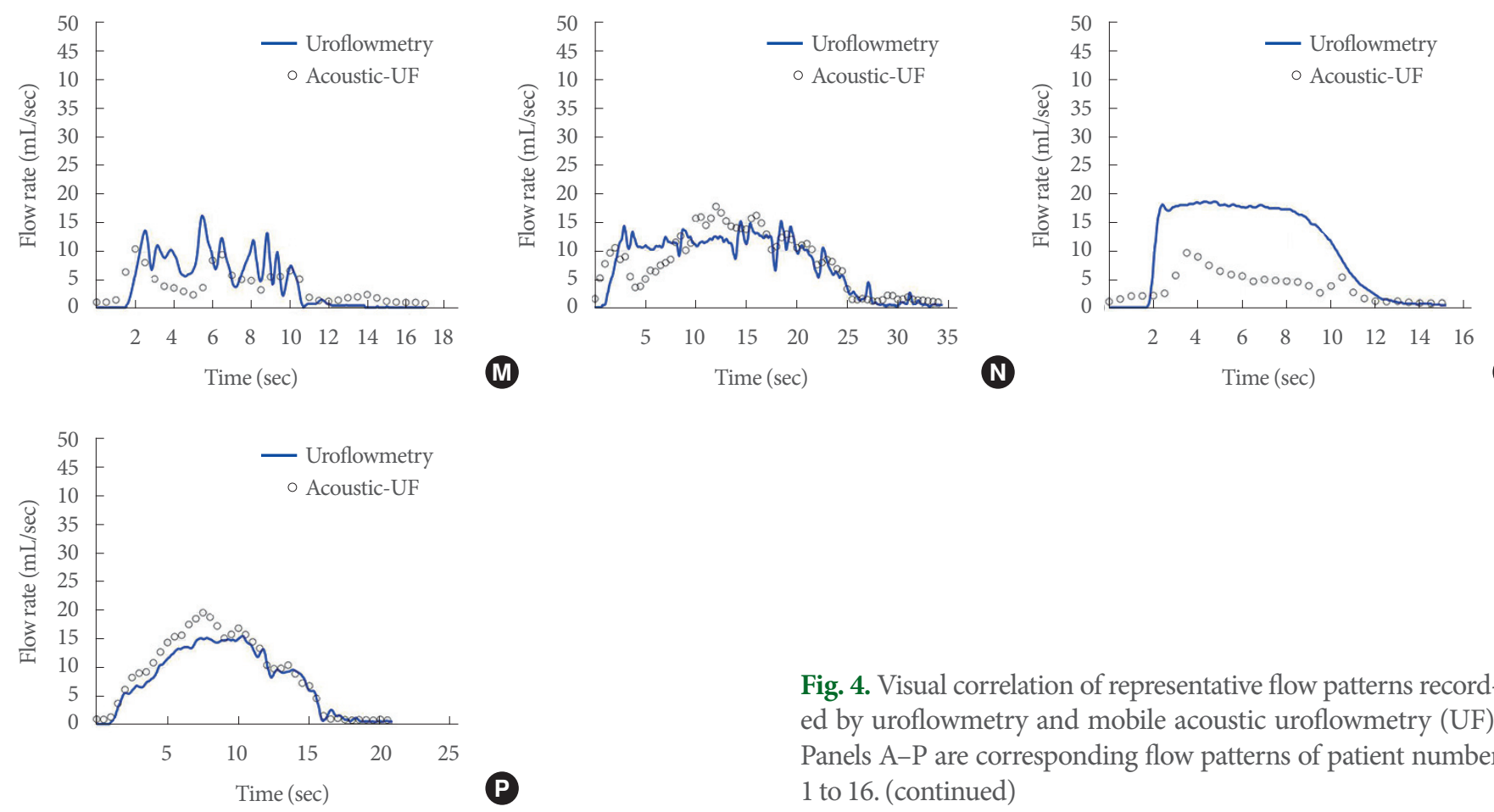

Fig. 4. Visual correlation of representative flow patterns recorded by uroflowmetry and mobile acoustic uroflowmetry (UF). Panels A-P are corresponding flow patterns of patient number 1 to 16 . (continued)

rable to the standard UFM method, with good visual correlations of the flow curves, and it provided reliable estimations of UFM results.

The prevalence of LUT symptoms in children has been reported to be between $9.3 \%$ and $56.2 \%$ [1,9-11]. LUT symptoms affect children and adolescents and can cause emotional and behavioral problems [12]. Children with these symptoms are also at risk of experiencing stressful social situations, as well as comorbidities such as urinary tract infections and vesicoureteral reflux [2]. Therefore, a timely and precise diagnosis is essential for these patients.

UFM with PVR measurement is a useful diagnostic test for a thorough evaluation of LUT symptoms in children, as it evaluates the emptying ability of the bladder. A graphical plot of the flow rate over time, VT, and Qmax based on the uroflow data is used to diagnose urinary outflow obstruction or LUT dysfunction. Notably, UFM is a rapid and straightforward noninvasive diagnostic method. However, a single UFM test may not be sufficient for clinical interpretation, and multiple tests are often required [2,3]. Consequently, children and their guardians often need to visit the clinic more than once, or spend additional clinic time to allow for bladder filling after the first test to undergo repeat testing. In contrast, mUFM is based on the sound of voiding while at home, which not only provides convenience for patients and guardians but also guarantees complete privacy and comfort because the patient can use their home bathroom during the test while avoiding travel to a clinic.

The PRIVY application records the sounds generated when a urine stream hits a funnel receptacle. Sound-based UFM has previously been described in the literature. Krhut et al. [5] performed a comparative analysis of UFM and sound-based UFM involving 25 healthy males. They used a collecting chamber filled with 3,000 $\mathrm{mL}$ of water and recorded the sound produced by the urine stream hitting the water surface. They showed that the correlation for Qmax was weak (Pearson correlation coefficient $=0.38$ ); however, the correlations for flow time and VV were strong (Pearson correlation coefficient $=0.87$ ) and moderate (Pearson correlation coefficient $=0.68$ ), respectively. In a subsequent comparative analysis involving 36 healthy women with a similar study setting and using the same type of smartphone (Samsung GT-B2710; Samsung, Seoul, Korea), Gartner et al. [13] also reported a weak correlation for Qmax (Pearson correlation coefficient $=0.38$ ).

The correlations between UFM and mUFM for Qmax, VT, and VV were strong in the present pediatric study (ICC $=0.755$, ICC $=0.974$, and ICC $=0.930$, respectively). This difference relative to previous studies may be attributed to the method of generating the estimated sound-based UFM curve in the present 
study. The PRIVY application uses an algorithm from a former validation study involving an adult population [8]. Furthermore, the application showed the estimated Qmax as a result and not the peak sound intensity, as demonstrated in a previous study. Another notable difference is that, in contrast to previous studies, the sound generated when the urine stream hit the wall of the funnel without water (not the surface of the water in the collecting chamber) was used. When the sound is recorded at the point of contact between the water surface and the urine stream, the majority of the sound may be attributed to the generation of air bubbles formed below the water surface (the splash phenomenon), resulting in wide acoustic spectra $[5,13]$. In the present study, the higher correlation of UFM parameters may be explained by the absence of this splash phenomenon.

The use of raw sound data may be another factor contributing to the difference in the correlation. In a previous study of sound-based UFM, the authors pointed out that one of the technical problems in their trial was the cell phone microphone technology, specifically the noise-cancellation system [5]. They reported that the reduced signal due to signal processing led to random artifacts in the sound recording. In the present study, signal processing by the smartphone was bypassed in the application, which allowed for raw sound data acquisition. The developed algorithm was then applied to minimize background noise during urination.

To overcome the limitations of clinic-based UFM, which requires patients to take time to fill their bladder for a repeat test, various devices other than smartphones have been introduced for home UFM [14]. Funnel devices are simple, low-cost instruments, but they require a measuring container and usually report a range of Qmax without information about the flow curve pattern $[15,16]$. Electronic flowmeters for home use can measure the full flow trace and VV without the need for the user to document the result; however, they require the user to install or carry an additional device [17-19]. A smartphone-based application would be more accessible as no devices other than the smartphone are required, and the results can be immediately displayed on the smartphone screen.

The goal of using a smartphone-based mUFM application is not to replace the conventional UFM method or the in-person diagnostic process, but to improve the diagnostic capabilities by enabling additional testing at home. Notably, LUT dysfunction can be identified from the shape of the flow curve; however, reliable information about its cause cannot be determined solely from the pattern [3]. The ICCS guidelines discourage the use of
UFM without EMG except during follow-up [3]. Therefore, in the pediatric clinical environment, mUFM may be beneficial for children who have undergone corrective surgery for hypospadias and those who require follow-up for the medical treatment of LUT symptoms. The mUFM application on a smartphone could be an accessible and convenient tool to assist in the clinical diagnosis of childhood LUT dysfunction.

This study has limitations. First, the number of patients was small. Although validation studies in the adult population have been conducted, further studies in the pediatric population with more patients and a more complex history of urologic diseases are needed. Second, we used only 1 type of smartphone in this study. The use of the PRIVY application for pediatric patients should be evaluated with different types of smartphones. The correlation between UFM and mUFM with various types of smartphones and toilet settings with the natural environment in home bathrooms should be determined for this technology to enter broader use. Third, we only included male children in this study. Therefore, a further validation study in female children is warranted.

In conclusion, this study showed that mUFM using a smartphone was comparable to standard UFM, with high correlations among UFM parameters in male pediatric patients. The mUFM application could be an accessible and convenient tool to assist the clinical diagnosis of childhood LUT dysfunction. Further validation of its performance in different toilet settings is necessary for broader use.

\section{ACKNOWLEDGEMENTS}

The authors would like to thank our nurses (Imelda C. Salcedo, Melanie T. White, and Ni Zhang), research coordinators (Jordon King, Fatima Fazal, and Kara C. Toman), and advanced practice providers (Jessica Schuh, Sarah J. Phillips and Jacqueline G. Broda) for their valuable contributions to this manuscript. We also thank Sung-Cheol Yun, $\mathrm{PhD}$, for his assistance with the statistical analysis. This study was presented at the Societies of Pediatric Urology meeting in 2020.

\section{AUTHOR CONTRIBUTION STATEMENT}

- Conceptualization: CJK, SHS

- Data curation: DGL, JG, VB, NJ, PFA, CJK, SHS

- Formal analysis: $D G L, J G, V B, N J, P F A, S H S$

- Methodology: JG, VB, NJ, PFA, CJK, SHS 
- Project administration: DGL, PFA, CJK, SHS

- Visualization: DGL, CJK, SHS

-Writing-original draft: $D G L, C J K, S H S$

- Writing-review \& editing: $D G L, C J K, S H S$

\section{ORCID}

$\begin{array}{ll}\text { Dong-Gi Lee } & 0000-0001-7369-9252 \\ \text { Jonathan Gerber } & 0000-0001-6297-8344 \\ \text { Vinaya Bhatia } & 0000-0003-0258-8998 \\ \text { Nicolette Janzen } & 0000-0002-9276-8433 \\ \text { Paul F. Austin } & 0000-0003-3654-9524 \\ \text { Chester J. Koh } & 0000-0001-8696-5193 \\ \text { Sang Hoon Song } & 0000-0003-4888-483 X\end{array}$

\section{REFERENCES}

1. Linde JM, Nijman RJM, Trzpis M, Broens PMA. Prevalence of urinary incontinence and other lower urinary tract symptoms in children in the Netherlands. J Pediatr Urol 2019;15:164.e1-7.

2. Tekgul S, Stein R, Bogaert G, Undre S, Nijman RJM, Quaedackers J, et al. EAU-ESPU guidelines recommendations for daytime lower urinary tract conditions in children. Eur J Pediatr 2020;179:106977.

3. Bauer SB, Nijman RJ, Drzewiecki BA, Sillen U, Hoebeke P; International Children's Continence Society Standardization S. International Children's Continence Society standardization report on urodynamic studies of the lower urinary tract in children. Neurourol Urodyn 2015;34:640-7.

4. Kluytmans-van den Bergh MFQ, Buiting AGM, Pas SD, Bentvelsen RG, van den Bijllaardt W, van Oudheusden AJG, et al. Prevalence and clinical presentation of health care workers with symptoms of coronavirus disease 2019 in 2 Dutch hospitals during an early phase of the pandemic. JAMA Netw Open 2020;3:e209673.

5. Krhut J, Gartner M, Sykora R, Hurtik P, Burda M, Lunacek L, et al. Comparison between uroflowmetry and sonouroflowmetry in recording of urinary flow in healthy men. Int J Urol 2015;22:761-5.

6. Lunacek L, Gartner M, Krhut J, Mika D, Sykora R, Zvara P. Evaluation of intra-individual test-re-test variability of uroflowmetry in healthy women and women suffering from stress, urge, and mixed urinary incontinence. Int Urogynecol J 2018;29:1523-7.
7. ICS 2018 Philadelphia Scientific Programme. Neurourol Urodyn 2018;37:1-430.

8. Lee YJ, Kim MM, Song SH, Lee S. A novel mobile acoustic uroflowmetry: comparison with contemporary uroflowmetry. Int Neurourol J 2021;25:150-6.

9. Akil IO, Ozmen D, Cetinkaya AC. Prevalence of urinary incontinence and lower urinary tract symptoms in school-age children. Urol J 2014;11:1602-8.

10. Vaz GT, Vasconcelos MM, Oliveira EA, Ferreira AL, Magalhaes PG, Silva FM, et al. Prevalence of lower urinary tract symptoms in school-age children. Pediatr Nephrol 2012;27:597-603.

11. Yuksel S, Yurdakul AC, Zencir M, Corduk N. Evaluation of lower urinary tract dysfunction in Turkish primary schoolchildren: an epidemiological study. J Pediatr Urol 2014;10:1181-6.

12. Dourado ER, de Abreu GE, Santana JC, Macedo RR, da Silva CM, Rapozo PMB, et al. Emotional and behavioral problems in children and adolescents with lower urinary tract dysfunction: a populationbased study. J Pediatr Urol 2019;15:376 e1-7.

13. Gartner M, Krhut J, Hurtik P, Burda M, Zvarova K, Zvara P. Evaluation of voiding parameters in healthy women using sound analysis. Low Urin Tract Symptoms 2018;10:12-6.

14. Bray A, Griffiths C, Drinnan M, Pickard R. Methods and value of home uroflowmetry in the assessment of men with lower urinary tract symptoms: a literature review. Neurourol Urodyn 2012;31:712.

15. Pel JJ, van Mastrigt R. Development of a low-cost flow meter to grade the maximum flow rate. Neurourol Urodyn 2002;21:48-54.

16. Pridgeon S, Harding C, Newton D, Pickard R. Clinical evaluation of a simple uroflowmeter for categorization of maximum urinary flow rate. Indian J Urol 2007;23:114-8.

17. Porru D, Scarpa RM, Prezioso D, Bertaccini A, Rizzi CA, Group HS. Home and office uroflowmetry for evaluation of LUTS from benign prostatic enlargement. Prostate Cancer Prostatic Dis 2005; 8:45-9.

18. Jorgensen JB, Jacobsen HL, Bagi P, Hvarnes H, Colstrup H. Home uroflowmetry by means of the $\mathrm{Da}$ Capo home uroflowmeter. Eur Urol 1998;33:64-8.

19. Golomb J, Lindner A, Siegel Y, Korczak D. Variability and circadian changes in home uroflowmetry in patients with benign prostatic hyperplasia compared to normal controls. J Urol 1992;147:1044-7. 